\title{
Association between type of anesthesia and length of hospital stay in primary unilateral total knee arthroplasty patients: a single-center retrospective study
}

\author{
Xiaoqing Wang ${ }^{1}, \mathrm{He} \mathrm{Li}^{2}$, Conghu Yuan ${ }^{1}$ and Hang Zhao ${ }^{1 *}$ (])
}

\begin{abstract}
Objective: This study explored the risk factors influencing the length of hospital stay (LOS) and establish whether the type of anesthesia is independently associated with the LOS in patients after primary unilateral total knee arthroplasty (TKA).

Methods: In this retrospective cohort study, 2309 patients undergoing unilateral TKA were recruited between January 2013 and June 2014 in a tertiary academic medical center in Singapore. Univariate and multivariate linear regression analyses were used to identify the independent risk factors associated with LOS. Besides, subgroup and interaction analyses were performed to evaluate the relationship between the type of anesthesia and LOS.

Result: In total, 2309 patients were identified. Out of these, 791 patients underwent general anesthesia, whereas 1518 patients underwent regional anesthesia. Multivariate regression analyses revealed that prolonged LOS was significantly associated with age $\geq 65$ years $(\beta=0.48 ; 95 \% \mathrm{Cl}, 0.09-0.87 ; P=0.015)$, diabetes mellitus (DM) $(\beta=0.8$; $95 \% \mathrm{Cl}, 0.33-1.27 ; P=0.001)$, congestive cardiac failure (CCF) $(\beta=4.1 ; 95 \% \mathrm{Cl}, 2.02-6.17 ; P<0.001)$, perioperative blood transfusion $(\beta=5.71 ; 95 \% \mathrm{Cl}, 4.86-6.56 ; P<0.001)$, creatinine $>2 \mathrm{mg} / \mathrm{dL}(\beta=4.54 ; 95 \% \mathrm{Cl}, 2.46-6.62 ; P<0.001)$, ASA status (III) $(\beta=1.72 ; 95 \% \mathrm{Cl}, 0.72-2.71 ; P=0.001)$, general anesthesia $(\beta=0.78 ; 95 \% \mathrm{Cl}, 0.41-1.66 ; P<0.001)$. The LOS further decreased among participants receiving regional anesthesia at advanced age (age $\geq 65$ years) $(\beta=-1.12$; $95 \% \mathrm{Cl},-1.66$ to $-0.58 ; P<0.001)$, patients with $\mathrm{BMI} \leq 25 \mathrm{~kg} / \mathrm{m}^{2}(\beta=-1.92 ; 95 \% \mathrm{Cl},-2.73$ to $-1.11 ; P<0.001)$ or $\geq 30 \mathrm{~kg} / \mathrm{m}^{2}(\beta=-0.58 ; 95 \% \mathrm{Cl},-1.1$ to $-0.06 ; P=0.029)$.

Conclusion: Our findings demonstrated that age $\geq 65$ years, DM, CCF, perioperative blood transfusion, creatinine $>2 \mathrm{mg} / \mathrm{dL}$, ASA status (III), general anesthesia are associated with a prolonged LOS after primary TKA. Elderly patients (age $\geq 65$ years) and patients with $\mathrm{BMI} \leq 25 \mathrm{~kg} / \mathrm{m}^{2}$ or $\geq 30 \mathrm{~kg} / \mathrm{m}^{2}$ receiving regional anesthesia have a further reduced LOS. Therefore, when TKA is performed, priority for regional anesthesia is given to the elderly patients (age $\geq 65$ years old) and those with $\mathrm{BMI} \leq 25 \mathrm{~kg} / \mathrm{m}^{2}$ or $\geq 30 \mathrm{~kg} / \mathrm{m}^{2}$.
\end{abstract}

Keywords: Type of anesthesia, Length of hospital stay, Total knee arthroplasty, Retrospective study

\footnotetext{
*Correspondence: zhaohang17777@163.com

1 Department of Anesthesiology, Affiliated Yancheng Hospital, School

of Medicine, Southeast University, Juchang Road, Yandu District, Yancheng City, Jiangsu Province, China

Full list of author information is available at the end of the article
}

\section{Introduction}

With the aging population, there has been a significant increase in the number of people suffering from arthritis. The World Health Organization (WHO) has globally estimated that over 250 million individuals are affected by original author(s) and the source, provide a link to the Creative Commons licence, and indicate if changes were made. The images or other third party material in this article are included in the article's Creative Commons licence, unless indicated otherwise in a credit line to the material. If material is not included in the article's Creative Commons licence and your intended use is not permitted by statutory regulation or exceeds the permitted use, you will need to obtain permission directly from the copyright holder. To view a copy of this licence, visit http://creativecommons.org/licenses/by/4.0/. The Creative Commons Public Domain Dedication waiver (http://creativeco mmons.org/publicdomain/zero/1.0/) applies to the data made available in this article, unless otherwise stated in a credit line to the data. 
arthritis, causing significant disability and reduced quality of life [1]. Knee osteoarthritis (KOA) is the most prevalent degenerative disorder of joints with chronic pain and mobility restraint [2]. Notably, total knee arthroplasty (TKA) is the most effective surgical procedure for end-stage osteoarthritis [3, 4]. In 2018, over 1.3 million TKA cases were performed in the United States, this number is annually increasing [5]. Meanwhile, the cases of TKA increased from 53,880 to 374,833 in mainland China within the recent 10 years, i.e., a 5.9-fold increase [6]. An increasing incidence of TKA poses a significant economic burden to the healthcare system. For instance, US medicare expenditure has statistically continued to increase and currently accounts for approximately $18 \%$ of the economy [7]. Thus, the health care system is struggling to guarantee quality health care and reduce hospital costs $[8,9]$. Length of hospital stay (LOS) has a significant effect on overall healthcare expenditure and is considered a clinical proxy for the value of care. Generally, LOS is considered a critical measurement of healthcare efficiency and resource utilization [10]. Reduced LOS minimizes the infection risk and medication side effects [11]. It improves the treatment quality and increases hospital profit with efficient bed management [12]. LOS may be influenced by several factors, including patient characteristics (age, gender, BMI, comorbidities, the American Society of Anesthesiologists (ASA) classification); perioperative management (anesthesia type, blood management) [13], surgical characteristics (approach, prosthesis design,duration time) [14-16], postoperative management (mobilization timing, postoperative pain) [17-21], and postoperative complication before discharge (infection, deep vein thrombosis) [11].

Anesthesia is an important step to ensure the success of the surgery. Therefore, the selection of an anesthetic method is of utmost importance for the outcomes of patients undergoing TKA. General and/or regional anesthesia is appropriate for TKA and is familiar to most anesthesiologists. Anesthesiologists typically select the type of anesthesia based on their practice style and various patient-related factors. General anesthesia is associated with higher rates of postoperative nausea, vomiting, and delirium. On the other hand, regional anesthesia may be complicated by block failure and destructive complications including epidural abscess, spinal hematoma, and nerve injury [22]. The complications above prolong the LOS. However, an anesthetic method that causes reduced LOS in TKA patients is not known.

Previous studies investigating the relationship between anesthetic technique and outcomes revealed that patients undergoing TKA under regional anesthesia had reduced LOS compared to those undergoing general anesthesia $[23,24]$. Nonetheless, recent high-quality randomized controlled trials on the relationship between anesthetic technique and outcomes in TKA patients have yielded conflicting results $[25,26]$. This study seeks to identify the risk factors influencing LOS and examine the relationship of anesthetic technique with LOS among patients undergoing TKA in a tertiary academic medical center in Singapore between January 2013 and June 2014. We speculated that regional anesthesia is associated with reduced LOS compared to general anesthesia.

\section{Materials and methods}

\section{Data sources}

This retrospective population study was conducted using data from the Dryad Digital Repository (https:// datadryad.org/stash/dataset/doi:10.5061/dryad.73250). This website permitted users to freely download the raw data. Authors of the original study have authorized the ownership of the original data to the data-dryad Web site. According to Dryad Terms of Service, we cited Dryad data Package for secondary analysis on a different hypothesis without infringing on the authors' rights.

\section{Study population}

We retrospectively analyzed data of 2622 patients, who underwent TKA between January 2013 and June 2014 in a tertiary academic medical centre in Singapore [27]. These clinical records were extracted from the institution's clinical information system (Sunrise Clinical Manager (SCM), Allscripts, Illinois, USA) and stored in their enterprise data repository and analytics system (SingHealth-IHiS Electronic Health Intelligence System), which integrates information from administration, clinical and ancillary healthcare systems. Additionally, Institutional Review Board approval was obtained (Singhealth CIRB 2014/651/D) prior to the start of the study. In the present study, it was performed to address the relationship between the type of anesthesia and LOS. The target independent variable is type of anesthesia (regional anesthesia and general anesthesia) and the dependent variable was LOS obtained at baseline. The LOS was defined as time from the date of hospital admission to the date of discharge. After excluding 22 patients who underwent revised TKA and 206 patients who underwent bilateral TKA, 57 patients with missing BMI, 28 patients who underwent a compound type of anesthesia. A total of 2309 patients underwent primary unilateral TKA were recruited for the final analysis (Fig. 1).

\section{Measurement of covariants}

Data was obtained the clinical information from the Dryad Digital Repository. Covariates included in this study were treated as potential confounding factors on the relationship of type of anesthesia and LOS in 
2622 participants extracted from DRYAD

database between 2013 and 2014

2309 participants were included in this study

Fig. 1 Flowchart detailing the selection process for patients included in this retrospective analysis

TKA patients based on previous studies. The major covariates of this study included patient demographics such as age, sex, race, body mass index (BMI); preoperative comorbidities such as smoking, preoperative hemoglobin $(\mathrm{Hb})$ level,American Society of Anesthesiologist Physical Status (ASA-PS) score, individual components of the Revised Risk Cardiac Index (RCRI), such as a history of previous cerebrovascular accidents (CVAs), ischaemic heart disease (IHD), congestive cardiac failure (CCF), diabetes mellitus (DM) and elevated preoperative creatinine level $>2 \mathrm{mg} / \mathrm{dL}$; details of the operation such as duration of operation, perioperative blood transfusion. American Society of Anesthesiologists-Physical Status (ASA-PS) follows that of the ASA-PS definitions. Perioperative blood transfusion was defined as within 2 weeks prior to surgery to 2 weeks following surgery. By convention, antiplatelet medications (except aspirin) were discontinued for the recommended duration before the procedure. the use of intravenous tranexamic acid and intraarticular tranexamic acid intra-operatively and drainage tube implantation into the joint post-operatively were not standardized. All patients received standard postoperative care of TKA protocol. This included subcutaneous administration of $40 \mathrm{mg}$ low molecular weight heparin (Clexane, Sanofi, Paris, France) once daily for thromboembolism prophylaxis on the first postoperative day until discharge. Patients who met the following specified criteria established by the surgeon and physiotherapist were discharged from the hospital: owning the ability to flex the operated knee close to $90^{\circ}$, turn around with the assistance of a walking frame and climb up a few steps.

\section{Statistical analysis}

The distribution of continuous variables was described with the use of the mean and the standard deviation (SD) or the median and the interquartile range [IQR]. Categorical variables were presented as proportions and percentages of the total. For confounders with partial missing data, if it is a categorical variable, we directly treated it as a new independent group; if it is a continuous variable, we replaced it with an average or median value. The differences between groups were checked by $x^{2}$ test or Fisher's Exact test for categorical variables or by the student's t-test or Mann-Whitney $U$ test for continuous variables. Multivariate linear regression models were utilized to calculate regression coefficients $\beta$ and $95 \%$ confidence interval (CI) for estimating the association between type of anesthesia and LOS. We estimated three models: Model 1 did not adjust any confounders. Model 2 adjusted for age, sex, and race. Model 3 additionally adjusted for age, sex, race, BMI, smoking, preoperative $\mathrm{Hb}$ level, DM, perioperative blood transfusion, Creatinine $>2 \mathrm{mg} / \mathrm{dL}$, previous IHD, CCF, CVA, ASA-PS, duration of operation. Interaction and stratified analyses were conducted according to age ( $<65$ and $\geq 65$ years), gender (male and female), BMI $\left(<25,25-29.9\right.$ and $\left.\geq 30 \mathrm{~kg} / \mathrm{m}^{2}\right)$, $\mathrm{Hb}(<11,11-12.9$ and $\geq 13 \mathrm{~g} / \mathrm{dL}$ ), ASA status (I, II and III), operation duration ( $<60,60-89$ and $\geq 90 \mathrm{~min})$, DM (diabetes and non-diabetes). Subgroup analyses were performed using stratified linear regression models. Account for non-linear relationship between age or BMI and LOS by category of anesthetic methods, we also used Generalized additive model and the smooth curve fitting (penalized spline method) to address nonlinearity. $P<0.05$ was considered statistically significant. This study adheres to 
Table 1 Baseline characteristics of patients

\begin{tabular}{|c|c|c|c|c|}
\hline Variables & Total $(n=2309)$ & $\mathrm{GA}(n=791)$ & $\mathrm{RA}(n=1518)$ & $P$ values \\
\hline \multicolumn{5}{|l|}{ Patient demographics } \\
\hline Race, $n(\%)$ & & & & 0.019 \\
\hline Chinese & $1945(84.2)$ & $642(81.2)$ & $1303(85.8)$ & \\
\hline Malay & $159(6.9)$ & $63(8)$ & $96(6.3)$ & \\
\hline Indian & $137(5.9)$ & $61(7.7)$ & $76(5)$ & \\
\hline Others & $68(2.9)$ & $25(3.2)$ & $43(2.8)$ & \\
\hline Gender, $n(\%)$ & & & & 0.003 \\
\hline Female & $1746(75.6)$ & $628(79.4)$ & $1118(73.6)$ & \\
\hline Male & $563(24.4)$ & $163(20.6)$ & $400(26.4)$ & \\
\hline $\mathrm{BMI}\left(\mathrm{Kg} / \mathrm{m}^{2}\right)$ & $27.8 \pm 5.7$ & $28.0 \pm 4.7$ & $27.7 \pm 6.2$ & 0.338 \\
\hline Age(years) & $66.5 \pm 8.1$ & $64.7 \pm 8.3$ & $67.4 \pm 7.9$ & $<0.001$ \\
\hline ASA status, $n(\%)$ & & & & 0.009 \\
\hline 1 & $155(6.7)$ & $68(8.6)$ & $87(5.7)$ & \\
\hline$\|$ & $2016(87.3)$ & $668(84.5)$ & $1348(88.8)$ & \\
\hline III & $138(6.0)$ & $55(7)$ & $83(5.5)$ & \\
\hline \multicolumn{5}{|l|}{ Details of operation } \\
\hline LOS(Days) & $4.0(3.0,6.0)$ & $4.0(4.0,6.0)$ & $4.0(3.0,5.0)$ & $<0.001$ \\
\hline Operation duration (mins) & $75.0(65.0,95.0)$ & $80.0(65.0,95.0)$ & $75.0(65.0,95.0)$ & 0.228 \\
\hline Day of week of operation, $n(\%)$ & & & & 0.142 \\
\hline Monday & $381(16.5)$ & $144(18.2)$ & $237(15.6)$ & \\
\hline Tuesday & $526(22.8)$ & $184(23.3)$ & $342(22.5)$ & \\
\hline Wednesday & $395(17.1)$ & $126(15.9)$ & $269(17.7)$ & \\
\hline Thursday & $522(22.6)$ & $161(20.4)$ & $361(23.8)$ & \\
\hline Friday & $365(15.8)$ & $127(16.1)$ & $238(15.7)$ & \\
\hline Saturday & $120(5.2)$ & $49(6.2)$ & $71(4.7)$ & \\
\hline Perioperative blood transfusion, $n$ (\%) & & & & 0.021 \\
\hline No & $2200(95.3)$ & $742(93.8)$ & $1458(96)$ & \\
\hline Yes & $109(4.7)$ & $49(6.2)$ & $60(4)$ & \\
\hline \multicolumn{5}{|l|}{ Patient comorbidities } \\
\hline Preoperative Hb (g/dL) & $13.1 \pm 1.5$ & $13.1 \pm 1.5$ & $13.1 \pm 1.4$ & 0.57 \\
\hline Smoking, $n(\%)$ & & & & 0.069 \\
\hline No & $2088(90.4)$ & $728(92)$ & 1360 (89.6) & \\
\hline Yes & $221(9.6)$ & $63(8)$ & $158(10.4)$ & \\
\hline OSA, $n(\%)$ & & & & 0.672 \\
\hline No & $2098(90.9)$ & $722(91.3)$ & $1376(90.6)$ & \\
\hline Yes & $211(9.1)$ & $69(8.7)$ & $142(9.4)$ & \\
\hline $\mathrm{DM}, n(\%)$ & & & & 1.000 \\
\hline No & $1869(80.9)$ & $640(80.9)$ & $1229(81)$ & \\
\hline Yes & $440(19.1)$ & $151(19.1)$ & $289(19)$ & \\
\hline $\mathrm{HD}, n(\%)$ & & & & 0.950 \\
\hline No & $2184(94.6)$ & $749(94.7)$ & $1435(94.5)$ & \\
\hline Yes & $125(5.4)$ & $42(5.3)$ & $83(5.5)$ & \\
\hline$C C F, n(\%)$ & & & & 0.088 \\
\hline No & $2292(99.3)$ & $789(99.7)$ & $1503(99)$ & \\
\hline Yes & $17(0.7)$ & $2(0.3)$ & $15(1)$ & \\
\hline CVA, $n(\%)$ & & & & 1.000 \\
\hline No & $2266(98.1)$ & 776 (98.1) & 1490 (98.2) & \\
\hline Yes & $43(1.9)$ & $15(1.9)$ & $28(1.8)$ & \\
\hline
\end{tabular}


Table 1 (continued)

\begin{tabular}{|c|c|c|c|c|}
\hline Variables & Total $(n=2309)$ & $\mathrm{GA}(n=791)$ & $\mathrm{RA}(n=1518)$ & $P$ values \\
\hline Creatinine $>2 \mathrm{mg} / \mathrm{dL}, n(\%)$ & & & & 0.719 \\
\hline No & 2041 (88.4) & 702 (88.7) & $1339(88.2)$ & \\
\hline Yes & $17(0.7)$ & $7(0.9)$ & $10(0.7)$ & \\
\hline NA & 251 (10.9) & $82(10.4)$ & 169 (11.1) & \\
\hline
\end{tabular}

Data presented are mean \pm SD, median (Q1-Q3), or $n(\%)$

GA general anesthesia, RA regional anesthesia, BMI body mass index, ASA Status American Society of Anesthesiologist Physical Status, $H b$ hemoglobin, $L O S$ length of stay, OSA Obstructive sleep apnea, DM diabetes mellitus, IHD ischemic heart disease, CCF congestive cardiac failure, CVA cerebrovascular accidents, SD standard deviation, NA not recorded

the Strengthening the Reporting of Observational Studies in Epidemiology guidelines. All the analyses were performed with the statistical software packages $\mathrm{R}$ 3.3.2 (http://www.R-project.org, The R Foundation) and Free Statistics software versions 1.1.

\section{Results}

\section{Baseline characteristics of study subjects}

We identified 2622 patients underwent TKA between January 2013 and June 2014 in a tertiary academic medical centre in Singapore. After applying the exclusion criteria, the analysis sample included 2309 eligible patients (1746 female and 563 male). The characteristics of the subjects between the general anesthesia and regional anesthesia group are presented in Table 1. Among these, 791 (34.3\%) individuals received general anesthesia, 1518 $(65.7 \%)$ individuals received regional anesthesia. Of the total participants, $84.2 \%(n=1945)$ were Chinese, $6.9 \%$ $(n=159)$ Malay, $5.9 \%(n=137)$ Indian, and $2.9 \%(n=68)$ others. The mean age of the sample was 66.5 years old (SD 8.1). The median LOS was 4.0 days (IQR 3.0-6.0). The mean BMI was $27.8 \mathrm{~kg} / \mathrm{m}^{2}$ (SD 5.7). In the overall study population, patients who received regional anesthesia were older $(P<0.001,-$ Table 1$)$, more likely to be female $(P=0.003,-$ Table 1$)$ and to have shorter LOS $(P<0.001$, Table 1$)$, and tended not to require blood transfusion treatment $(P=0.021,-$ Table 1$)$.

\section{Risk factors and length of hospital stay}

The results of univariate analysis are presented in Table 2. The risk factors of prolonged LOS include that age $\geq 65$ years old $(\beta=0.77 ; 95 \%$ CI, $0.39-1.15 ; P<0.001)$, operation duration $\geq 90 \mathrm{~min} \quad(\beta=0.66 ; 95 \% \mathrm{CI}, 0.05-$ $1.28 ; P=0.03)$, general anesthesia $(\beta=0.84$; $95 \% \mathrm{CI}, 0.44-$ $1.23 ; P<0.001)$, perioperative blood transfusion $(\beta=6.81$; 95\% CI, 5.96-7.65; $P<0.001)$, ASA(III) $(\beta=2.95 ; 95 \%$ CI, 1.9-4; $P<0.001), \mathrm{DM}(\beta=1.03 ; 95 \% \mathrm{CI}, 0.55-1.51$; $P<0.001)$, IHD $(\beta=1.37 ; 95 \% \mathrm{CI}, 0.54-2.2 ; P=0.001)$, CCF $(\beta=6.5 ; 95 \%$ CI, 4.30-8.69; $P<0.001)$, creatinine $>2 \mathrm{mg} / \mathrm{dL}(\beta=6.86 ; 95 \% \mathrm{CI}, 4.67-9.06 ; P<0.001)$. In addition, multivariable logistic regression analyses are conducted for the independent effects of age, operation duration, type of anethesia, perioperative blood transfusion, ASA status, DM, IHD, CCF, creatinine $>2 \mathrm{mg} /$ $\mathrm{dL}$ in Table 3 . The result reveals that age $\geq 65$ years old $(\beta=0.48 ;$ 95\% CI, 0.09-0.87; $P=0.015)$, DM $(\beta=0.8$; 95\% CI, 0.33-1.27; $P=0.001), \operatorname{CCF}(\beta=4.1 ; 95 \% \mathrm{CI}$, $2.02-6.17 ; P<0.001)$, perioperative blood transfusion $(\beta=5.71 ; 95 \%$ CI, 4.86-6.56; $P<0.001)$, creatinine $>2 \mathrm{mg} /$ dL $\quad(\beta=4.54 ; \quad 95 \% \quad$ CI, 2.46-6.62; $P<0.001), \quad$ ASA status(III) $(\beta=1.72 ; 95 \% \mathrm{CI}, 0.72-2.71 ; P=0.001)$, general anesthesia $(\beta=0.78$; 95\% CI, $0.41-1.66 ; P<0.001)$ was significantly associated with prolonged LOS after adjusting for other covariates. So that LOS was 0.78 days longer in general anesthesia group compared with regional anesthesia group. In analysis, we further explored the association between type of anethesia and LOS. As shown in Table 4, the stratified analysis revealed a highly consistent pattern. Regardless of subgroup, effect size of type of anethesia on LOS were stable. The interaction analysis revealed that age $(P$ for interaction $=0.006)$ and BMI $(P$ for interaction $=0.01$ ) played an interactive role in the association between type of anethesia and LOS (Table 4 ). The participants aged $\geq 65$ years old $(\beta=-1.12$; 95\% CI, -1.66 to $-0.58 ; P<0.001)$ had shorter LOS in regional anesthesia group than those aged $<65$ years old $(\beta=-0.27 ; 95 \% \mathrm{CI},-0.73$ to $0.19 ; P=0.247)$. The association between age and LOS in different anesthesia group is presented in Addtional file 1. In addition, participants with $\mathrm{BMI}<25 \mathrm{~kg} / \mathrm{m}^{2}(\beta=-1.92 ; 95 \% \mathrm{CI}$, - 2.73 to $-1.11 ; P<0.001)$ or $\geq 30 \mathrm{~kg} / \mathrm{m}^{2} \quad(\beta=-0.58$; $95 \% \mathrm{CI},-1.1$ to $-0.06 ; P=0.029)$ had a shorter LOS in regional anesthesia group in than BMI at $25-30 \mathrm{~kg} / \mathrm{m}^{2}$ $(\beta=-0.31 ; 95 \% \mathrm{CI},-0.92$ to $0.29 ; P=0.313)$. The association between BMI and LOS in different anesthesia group is presented in Addtional file 2.

\section{Discussion}

We retrospectively uncovered high-risk factors for prolonged LOS and evaluated the relationship between the anesthetic method and LOS in patients after primary unilateral TKA between January 2013 and June 2014. 
Table 2 Univariate analysis for LOS

\begin{tabular}{|c|c|c|}
\hline Covariate & $\beta(95 \% \mathrm{Cl})$ & $P$ value \\
\hline \multicolumn{3}{|c|}{ Patient demographics } \\
\hline \multicolumn{3}{|l|}{ Race } \\
\hline Chinese & Reference & \\
\hline Malay & $-0.44(-1.19,0.31)$ & 0.248 \\
\hline Indian & $0.12(-0.68,0.92)$ & 0.766 \\
\hline Others & $0.51(-0.61,1.63)$ & 0.368 \\
\hline \multicolumn{3}{|l|}{ Gender } \\
\hline Female & Reference & \\
\hline Male & $-0.1(-0.54,0.34)$ & 0.669 \\
\hline \multicolumn{3}{|l|}{ Age(years) } \\
\hline$<65$ & Reference & \\
\hline$\geq 65$ & $0.77(0.39,1.15)$ & $<0.001$ \\
\hline \multicolumn{3}{|l|}{ BMI $\left(\mathrm{kg} / \mathrm{m}^{2}\right)$} \\
\hline$<25$ & Reference & \\
\hline $25-29.9$ & $-0.29(-0.74,0.16)$ & 0.205 \\
\hline$\geq 30$ & $0.26(-0.76,0.23)$ & 0.299 \\
\hline \multicolumn{3}{|c|}{ Details of operation } \\
\hline \multicolumn{3}{|c|}{ Type of Anaesthesia } \\
\hline GA & $0.84(0.44,1.23)$ & $<0.001$ \\
\hline RA & Reference & \\
\hline \multicolumn{3}{|c|}{ Operation duration (mins) } \\
\hline$<60$ & Reference & \\
\hline $60-90$ & $0.16(-0.42,0.73)$ & 0.594 \\
\hline$\geq 90$ & $0.66(0.05,1.28)$ & 0.033 \\
\hline \multicolumn{3}{|c|}{ Day of week of operation } \\
\hline Monday & $1.26(0.66,1.87)$ & $<0.001$ \\
\hline Tuesday & $1.00(0.44,1.56)$ & $<0.001$ \\
\hline Wednesday & $0.74(0.14,1.34)$ & 0.016 \\
\hline Thursday & Reference & \\
\hline Friday & $1.5(0.88,2.11)$ & $<0.001$ \\
\hline Saturday & $0.11(-0.81,1.02)$ & 0.82 \\
\hline \multicolumn{3}{|c|}{ Perioperative blood transfusion } \\
\hline No & Reference & \\
\hline Yes & $6.81(5.96,7.65)$ & $<0.001$ \\
\hline \multicolumn{3}{|c|}{ Patient comorbidities } \\
\hline \multicolumn{3}{|c|}{ ASA status } \\
\hline 1 & Reference & \\
\hline$\|$ & $0.37(-0.38,1.12)$ & 0.339 \\
\hline III & $2.95(1.9,4)$ & $<0.001$ \\
\hline \multicolumn{3}{|c|}{ Preoperative $\mathrm{Hb}(\mathrm{g} / \mathrm{dL})$} \\
\hline$<11$ & $1.28(0.51,2.05)$ & 0.001 \\
\hline $11-12.9$ & $0.63(0.24,1.03)$ & 0.002 \\
\hline$\geq 13$ & Reference & \\
\hline \multicolumn{3}{|l|}{ Smoking } \\
\hline No & Reference & \\
\hline Yes & $-0.37(-1.02,0.27)$ & 0.253 \\
\hline \multicolumn{3}{|l|}{ OSA } \\
\hline No & Reference & \\
\hline Yes & $-0.51(-1.16,0.15)$ & 0.129 \\
\hline
\end{tabular}

Table 2 (continued)

\begin{tabular}{llr}
\hline Covariate & $\boldsymbol{\beta}(\mathbf{9 5} \% \mathbf{C l})$ & $\boldsymbol{P}$ value \\
\hline DM & & \\
No & Reference & \\
Yes & $1.03(0.55,1.51)$ & $<0.001$ \\
IHD & & \\
No & Reference & 0.001 \\
Yes & $1.37(0.54,2.2)$ & \\
CCF & & \\
No & Reference & \\
Yes & $6.5(4.30,8.69)$ & \\
CVA & & 0.001 \\
No & Reference & \\
Yes & $1.04(-0.36,2.44)$ & \\
Creatinine $>2 \mathrm{mg} / \mathrm{dL}$ & & $<0.001$ \\
No & Reference & 0.770 \\
Yes & $6.86(4.67,9.06)$ & \\
NA & $0.09(-0.51,0.69)$ & \\
\hline
\end{tabular}

GA general anesthesia, $R A$ regional anesthesia, $B M I$ body mass index, ASA Status American Society of Anesthesiologist Physical Status, $\mathrm{Hb}$ haemoglobin, LOS length of stay, OSA Obstructive sleep apnea, DM diabetes mellitus, IHD ischemic heart disease, CCF congestive cardiac failure, CVA cerebrovascular accidents, SD standard deviation, NA not recorded

Age $\geq 65$ years, DM, CCF, ASA status (III), general anesthesia were significant and independent risks for prolonged LOS in patients after TKA. Moreover, regional anesthesia was associated with a shorter hospital LOS compared to general anesthesia in patients after primary unilateral TKA. Patients in the regional anesthesia group had a 0.78 days shorter LOS than those in the general anesthesia group. Moreover, subgroup and interaction analyses revealed that the relationship between regional anesthesia and a shorter hospital LOS is modified by age and BMI. A stronger relationship between anesthetic type and LOS was detected in elderly patients (age $\geq 65$ years) and those whose BMI was $\leq 25 \mathrm{~kg} / \mathrm{m}^{2}$ or $\geq 30 \mathrm{~kg} / \mathrm{m}^{2}$.

Consistent with our research findings, Gulraj $\mathrm{S}$ et al. performed a retrospective analysis of prospectively collected observational data from the National Joint Registry (NJR) and found that LOS $(\beta=-0.47$ days; $95 \%$ CI, -0.49 to $-0.45 ; P<0.001)$ was reduced with regional anesthesia compared to general anesthesia in patients undergoing TKA [24]. To our knowledge, so far, this study has the largest sample size $(n=426,104)$. In contrast with our study, given that BMI is frequently missing in the NJR, multivariable logistic regression analysis was performed for all patient and surgical factors excluding BMI. Besides, significant confounders were overlooked in covariates, including perioperative blood transfusion, and preoperative $\mathrm{Hb}$ level. 
Table 3 Multivariate analyses of risk factors associated with LOS

\begin{tabular}{|c|c|c|c|c|c|c|}
\hline & \multicolumn{2}{|l|}{ Model I } & \multicolumn{2}{|l|}{ Model II } & \multicolumn{2}{|l|}{ Model III } \\
\hline & $\beta(95 \% \mathrm{Cl})$ & $P$ value & $\beta(95 \% \mathrm{Cl})$ & $P$ value & $\beta(95 \% \mathrm{Cl})$ & $P$ value \\
\hline \multicolumn{7}{|l|}{ Age (years) } \\
\hline Per 10 & $0.68(0.45-0.91)$ & $<0.001$ & $0.69(0.46-0.93)$ & $<0.001$ & $0.5(0.27-0.73)$ & $<0.001$ \\
\hline$<65$ & Reference & & Reference & & Reference & \\
\hline$\geq 65$ & $0.77(0.39-1.15)$ & $<0.001$ & $0.77(0.38-1.16)$ & $<0.001$ & $0.48(0.09-0.87)$ & 0.015 \\
\hline \multicolumn{7}{|l|}{$\mathrm{Hb}(\mathrm{g} / \mathrm{dL})$} \\
\hline$<11$ & Reference & & Reference & & Reference & \\
\hline $11-12.9$ & $-0.65(-1.43$ to 0.14$)$ & 0.109 & $-0.62(-1.4$ to 0.17$)$ & 0.124 & $0.34(-0.41$ to 1.08$)$ & 0.374 \\
\hline$\geq 13$ & $-1.28(-2.05$ to -0.51$)$ & 0.001 & $-1.12(-1.89$ to -0.35$)$ & 0.004 & $0.13(-0.6$ to 0.87$)$ & 0.721 \\
\hline \multicolumn{7}{|l|}{ DM } \\
\hline No & Reference & & Reference & & Reference & \\
\hline Yes & $1.03(0.55-1.51)$ & $<0.001$ & $0.97(0.49-1.45)$ & $<0.001$ & $0.8(0.33-1.27)$ & 0.001 \\
\hline \multicolumn{7}{|l|}{ CCF } \\
\hline No & Reference & & Reference & & Reference & \\
\hline Yes & $6.5(4.3-8.69)$ & $<0.001$ & $6.28(4.1-8.47)$ & $<0.001$ & $4.1(2.02-6.17)$ & $<0.001$ \\
\hline \multicolumn{7}{|l|}{ IHD } \\
\hline \multicolumn{7}{|l|}{ No } \\
\hline \multicolumn{7}{|l|}{ Yes } \\
\hline \multicolumn{7}{|c|}{ Operation duration (mins) } \\
\hline$<60$ & Reference & & Reference & & Reference & \\
\hline 60-90 & $0.16(-0.42$ to 0.73$)$ & 0.594 & $0.19(-0.38$ to 0.77$)$ & 0.513 & $0.17(-0.37$ to 0.7$)$ & 0.544 \\
\hline$\geq 90$ & $0.66(0.05-1.28)$ & 0.033 & $0.72(0.11-1.32)$ & 0.021 & $0.49(-0.09$ to 1.07$)$ & 0.095 \\
\hline \multicolumn{7}{|c|}{ Perioperative blood transfusion } \\
\hline No & Reference & & Reference & & Reference & \\
\hline Yes & $6.81(5.96-7.65)$ & $<0.001$ & $6.62(5.77-7.47)$ & $<0.001$ & $5.71(4.86-6.56)$ & $<0.001$ \\
\hline \multicolumn{7}{|c|}{ Creatinine $>2 \mathrm{mg} / \mathrm{dL}$} \\
\hline No & Reference & & Reference & & Reference & \\
\hline Yes & $6.86(4.67-9.05)$ & $<0.001$ & $6.89(4.7-9.07)$ & $<0.001$ & $4.54(2.46-6.62)$ & $<0.001$ \\
\hline NA & $0.09(-0.51$ to 0.69$)$ & 0.77 & $0.11(-0.49$ to 0.71$)$ & 0.722 & $0.09(-0.47$ to 0.66$)$ & 0.744 \\
\hline \multicolumn{7}{|l|}{ ASA status } \\
\hline 1 & Reference & & Reference & & Reference & \\
\hline$\|$ & $0.37(-0.38-1.12)$ & 0.339 & $0.2(-0.55$ to 0.95$)$ & 0.596 & $0.15(-0.56$ to 0.85$)$ & 0.684 \\
\hline III & $2.95(1.9-4)$ & $<0.001$ & $2.68(1.62-3.73)$ & $<0.001$ & $1.72(0.72-2.71)$ & 0.001 \\
\hline \multicolumn{7}{|c|}{ Type of anesthesia } \\
\hline GA & $0.84(0.44-1.23)$ & $<0.001$ & $1.03(0.63-1.43)$ & $<0.001$ & $0.78(0.41-1.66)$ & $<0.001$ \\
\hline RA & Reference & & Reference & & Reference & \\
\hline
\end{tabular}

Data presented are $\beta$ and $95 \% \mathrm{Cls}$

Model I: We did not adjust any covariants

Model II: We adjusted age, gender and race

Model III: We adjusted age, gender, race, ASA status, Hb, smoking, Operation Duration, BMI, DM, creatinine $>2 \mathrm{mg} / \mathrm{dL}, \mathrm{IHD}, \mathrm{CCF}, \mathrm{CVA}$, Type of anesthesia, Day of week of operation and the perioperative blood transfusion. In each case, the model is not adjusted for the variable itself

GA general anesthesia, RA regional anesthesia, ASA Status American Society of Anesthesiologist Physical Status, Hb hemoglobin, DM diabetes mellitus, IHD ischemic heart disease, CCF congestive cardiac failure

This work utilized an extended model approach to adjust the potential confounders and performed subgroup and interaction analyses to ensure a stable relationship between the anesthetic method and LOS. One meta-analysis confirmed that regional anesthesia had a reduced LOS compared to general anesthesia in TKA and total hip replacement (THR); this was in line with our findings. However, this meta-analysis of LOS enrolled only 1240 patients undergoing TKA and THA who were not separately grouped. Our study 
Table 4 Effect size of type of anesthesia on LOS in each group

\begin{tabular}{|c|c|c|c|c|}
\hline Subgroup & $N$ & $\beta(95 \% \mathrm{Cl})$ & $P$ value & $P$ for interaction \\
\hline Age(years) & & & & 0.006 \\
\hline$<65$ & 940 & $-0.27(-0.73$ to 0.19$)$ & 0.247 & \\
\hline$\geq 65$ & 1369 & $-1.12(-1.66$ to -0.58$)$ & $<0.001$ & \\
\hline Gender & & & & 0.063 \\
\hline Female & 1746 & $-0.68(-1.08$ to -0.29$)$ & 0.001 & \\
\hline Male & 563 & $-1.31(-2.30$ to -0.31$)$ & 0.010 & \\
\hline Preoperative Hb (g/dL) & & & & 0.934 \\
\hline$<11$ & 156 & $-1.49(-2.68$ to -0.3$)$ & 0.015 & \\
\hline $11-12.9$ & 868 & $-0.78(-1.49$ to -0.07$)$ & 0.032 & \\
\hline$\geq 13$ & 1286 & $-0.79(-1.25$ to -0.34$)$ & 0.001 & \\
\hline $\mathrm{BMI}\left(\mathrm{kg} / \mathrm{m}^{2}\right)$ & & & & 0.01 \\
\hline$<25$ & 683 & $-1.92(-2.73$ to -1.11$)$ & $<0.001$ & \\
\hline $25-29.9$ & 986 & $-0.31(-0.92$ to 0.29$)$ & 0.313 & \\
\hline$\geq 30$ & 640 & $-0.58(-1.1$ to -0.06$)$ & 0.029 & \\
\hline ASA status & & & & 0.526 \\
\hline I & 155 & $-0.03(-0.79$ to 0.73$)$ & 0.934 & \\
\hline$\|$ & 2016 & $-0.85(-1.23$ to -0.48$)$ & $<0.001$ & \\
\hline III & 138 & $-1.12(-4.65$ to 2.41$)$ & 0.536 & \\
\hline Operation duration (mins) & & & & 0.817 \\
\hline$<60$ & 308 & $-1.1(-1.81$ to -0.39$)$ & 0.003 & \\
\hline $60-89$ & 1231 & $-0.82(-1.38$ to -0.26$)$ & 0.004 & \\
\hline$\geq 90$ & 773 & $-0.72(-1.37$ to -0.08$)$ & 0.028 & \\
\hline DM & & & & 0.061 \\
\hline No & 1869 & $-0.64(-1.02$ to -0.26$)$ & 0.001 & \\
\hline Yes & 440 & $-1.6(-2.69$ to -0.51$)$ & 0.004 & \\
\hline
\end{tabular}

We adjusted age, gender, race, ASA status, Hb, smoking, Operation Duration, BMI, DM, creatinine $>2$ mg/dL, IHD, CCF, CVA, Type of anesthesia, Day of week of operation and the perioperative blood transfusion. In each case, the model is not adjusted for the variable itself

$B M I$ body mass index, ASA Status American Society of Anesthesiologist Physical Status, $\mathrm{Hb}$ haemoglobin, DM diabetes mellitus

had a larger cohort including primary unilateral TKA $(n=2622)$. In contradiction with our study result, Jared et al. [28]. conducted a retrospective study of the TKA cohort $(n=183,080)$ using the American College of Surgeons National Surgical Quality Improvement Program (NSQIP) database between 2011 and 2016, describing a statistically significant but clinically irrelevant increase $(\mathrm{OR}=0.050 ; 95 \% \mathrm{CI}, 0.023-0.078$; $P<0.001)$. Unlike this study, LOS among those treated with general anesthesia was 0.78 days longer than those treated with regional anesthesia $(\beta=0.78 ; 95 \% \mathrm{CI}$, $0.41-1.66 ; P<0.001)$ after adjusting for other confounding factors and was statistically and clinically meaningful. Additionally, Harsten et al. [25]. discovered that general anesthesia resulted in shorter LOS compared to regional anesthesia among 124 patients with osteoarthritis undergoing TKA at the Department of Orthopaedic Surgery, Ha“ssleholm Hospital, Sweden between September 2011 and June 2012. Elsewhere, Palanne et al. [26]. found that spinal and general anesthesia did not differ in LOS among patients $(n=413)$ undergoing
TKA. Although the above studies are randomized controlled trials (RCTs), the sample size is small from a single center. Therefore, the generalizability of the findings is at stake.

This paper has notable strengths. First, we used a large sample size. Secondly, we evaluated the relationship between anesthetic type and hospital LOS; different multivariate logistic regression models were used to minimize bias by adjusting for other confounding factors. Furthermore, a subgroup analysis was performed to improve the robustness of the results. Consequently, age and BMI significantly affected the relationship between the type of anesthesia and LOS through interaction analysis.

Nevertheless, this study has compelling limitations. First, it is based on a retrospective analysis from a published database. Although we attempted to statistically correct the bias, we could not exclude unmeasured and/or residual confounding factors vital for the outcomes of hospital LOS, including the use of a different agent and its duration; intraoperative blood loss 
and postoperative care techniques; postoperative pain which potentially brings bias to the results. Secondly, as a cross-sectional study design, it has less power to infer the causal relationship between anesthetic type and LOS. Thus, additional prospective follow-up studies are necessary to verify these findings. Thirdly, most of the patients recruited were Chinese in Singapore; different races may cause different results. Therefore, our results cannot necessarily be generalized to people of other ethnicities in different countries. Notably, regional anesthesia included intrathecal anesthesia, nerve block anesthesia, and local anesthesia. Importantly, this study did not specify the regional anesthetic method that had been used. As such, further exploratory studies are essential to analyze a more suitable regional anesthesia for TKA from the perspective of shortening LOS in the next step.

\section{Conclusion}

In conclusion, the use of regional anesthesia is independently and positively related to shorter LOS compared to general anesthesia in patients after unilateral TKA. This impact is prominent among elderly patients (age $\geq 65$ years) and those with $\mathrm{BMI} \leq 25 \mathrm{~kg} /$ $\mathrm{m}^{2}$ or $\geq 30 \mathrm{~kg} / \mathrm{m}^{2}$. For anesthesiologists, it is essential to identify high-risk factors of prolonged LOS and select the most appropriate anesthetic type for patients with primary unilateral TKA. Herein, we recommend regional anesthesia as the primary anesthetic approach for primary unilateral TKA, specifically among the elderly patients (age $\geq 65$ years) and those with $\mathrm{BMI} \leq 25 \mathrm{~kg} / \mathrm{m}^{2}$ or $\geq 30 \mathrm{~kg} / \mathrm{m}^{2}$.

\section{Abbreviations}

BMI: Body mass index; ASA status: American Society of Anesthesiologist Physical status; Hb: Hemoglobin; TKA: Total knee arthroplasty; LOS: Hospital length of stay; OSA: Obstructive sleep apnea; DM: Diabetes mellitus; IHD: Ischemic heart disease; CCF: Congestive cardiac failure; CVA: Cerebrovascular accidents; SD: Standard deviation; NA: Not recorded; Cl: Confidence interval; GA: General anesthesia; RA: Regional anesthesia.

\section{Supplementary Information}

The online version contains supplementary material available at https://doi. org/10.1186/s13018-021-02817-4.

Additional file 1. The association between age and LOS in different anesthesia group.

Additional file 2. The association between BMI and LOS in different anesthesia group.

\section{Acknowledgements}

We gratefully thank all participants in this cohort study. We gratefully thank Abdullah HR for presenting raw data.

\section{Authors' contributions}

XQW and $\mathrm{HZ}$ conceived the study idea. $\mathrm{HL}$ and $\mathrm{CHY}$ analyzed the data. XQW reviewed the literature and wrote the first draft. $\mathrm{HZ}$ critically reviewed and edited the manuscript, and approved the final version. All authors read and approved the final manuscript.

\section{Funding}

This research did not receive any specific grant from funding agencies in the public, commercial, or not-for-profit sectors.

\section{Availability of data and materials}

Data can be downloaded from the Dryad Digital Repository. Dryad data package: Abdullah HR, Sim E, Hao Y, Lin G, Liew GHC, Lamoureux EL, Tan MH (2017). Data from: Association between preoperative anemia with length of hospital stay among patients undergoing primary total knee arthroplasty in Singapore: a single-center retrospective study. Dryad Digital Reposi-tory. https://doi.org/ 10.5061/dryad.73250.

\section{Declarations}

Ethics approval and consent to participate

Ethics was approved by the SingHealth Institutional Review Board. As this was a retrospective analysis of medical records, waiver of patient's consent was obtained from the ethics board.

\section{Consent for publication}

Not applicable.

\section{Competing interests}

The authors declare that they have no known competing financial interests or personal relationships that could have appeared to influence the work reported in this paper.

\section{Author details}

'Department of Anesthesiology, Affiliated Yancheng Hospital, School of Medicine, Southeast University, Juchang Road, Yandu District, Yancheng City, Jiangsu Province, China. ${ }^{2}$ Department of Anesthesiology, Affiliated Shuguang Hospital, Shanghai University of Traditional Chinese Medicine, Shanghai, China.

Received: 22 September 2021 Accepted: 1 November 2021

Published online: 15 November 2021

\section{References}

1. Global, regional, and national incidence, prevalence, and years lived with disability for 328 diseases and injuries for 195 countries, 1990-2016: a systematic analysis for the Global Burden of Disease Study 2016. Lancet (London, England) 2017;390(10100):1211-59.

2. Glyn-Jones S, Palmer AJ, Agricola R, Price AJ, Vincent TL, Weinans H, Carr AJ. Osteoarthritis. Lancet (London, England). 2015;386(9991):376-87.

3. Skou ST, Roos EM, Laursen MB, Rathleff MS, Arendt-Nielsen L, Simonsen $\mathrm{O}$, Rasmussen S. A randomized, controlled trial of total knee replacement. N Engl J Med. 2015;373(17):1597-606.

4. Carr AJ, Robertsson O, Graves S, Price AJ, Arden NK, Judge A, Beard DJ. Knee replacement. Lancet (London, England). 2012;379(9823):1331-40.

5. Cram P, Lu X, Kates SL, Singh JA, Li Y, Wolf BR. Total knee arthroplasty volume, utilization, and outcomes among Medicare beneficiaries, 1991-2010. JAMA. 2012;308(12):1227-36.

6. Feng B, Zhu W, Bian YY, Chang X, Cheng KY, Weng XS. China artificial joint annual data report. Chin Med J. 2020;134(6):752-3.

7. Dieleman JL, Cao J, Chapin A, Chen C, Li Z, Liu A, Horst C, Kaldjian A, Matyasz T, Scott KW, et al. US Health care spending by payer and health condition, 1996-2016. JAMA. 2020;323(9):863-84.

8. Smith CD. Teaching high-value, cost-conscious care to residents: the Alliance for Academic Internal Medicine-American College of Physicians Curriculum. Ann Intern Med. 2012;157(4):284-6.

9. Cross M, Smith E, Hoy D, Nolte S, Ackerman I, Fransen M, Bridgett L, Williams S, Guillemin F, Hill CL, et al. The global burden of hip and knee 
osteoarthritis: estimates from the global burden of disease 2010 study. Ann Rheum Dis. 2014;73(7):1323-30.

10. Fujiwara S, Zhao X, Teoh C, Jaffe DH, Taguchi Y. Disease burden of fractures among patients with osteoporosis in Japan: health-related quality of life, work productivity and activity impairment, healthcare resource utilization, and economic costs. J Bone Miner Metab. 2019;37(2):307-18.

11. Aicale R, Maffulli N. Lower limb joint repair and replacement: an overview. F1000Research 2019, 8.

12. Rotter T, Kinsman L, James E, Machotta A, Gothe H, Willis J, Snow P, Kugler J. Clinical pathways: effects on professional practice, patient outcomes, length of stay and hospital costs. Cochrane Database Syst Rev. 2010;3:CD006632

13. Pennestrì F, Maffulli N, Sirtori P, Perazzo P, Negrini F, Banfi G, Peretti GM. Blood management in fast-track orthopedic surgery: an evidence-based narrative review. J Orthop Surg Res. 2019;14(1):263.

14. Benazzo F, Perticarini L, Jannelli E, Ivone A, Ghiara M, Rossi SMP. Controversy: supporting patellar resurfacing in total knee arthroplasty—do it. EFORT Open Rev. 2020;5(11):785-92.

15. Parsons T, Al-Jabri T, Clement ND, Maffulli N, Kader DF. Patella resurfacing during total knee arthroplasty is cost-effective and has lower re-operation rates compared to non-resurfacing. J Orthop Surg Res. 2021;16(1):185.

16. Benazzo F, Jannelli E, Ivone A, Formagnana M, Rossi SM, Ghiara M, Danesino G, Mosconi M. Knee arthroplasty system with medialized keel: Seven-year follow-up of a pioneer cohort. Knee. 2020;27(3):624-32.

17. Smith ID, Elton R, Ballantyne JA, Brenkel IJ. Pre-operative predictors of the length of hospital stay in total knee replacement. J Bone Joint Surg Br. 2008;90(11):1435-40.

18. Mertes SC, Raut S, Khanduja V. Integrated care pathways in lower-limb arthroplasty: Are they effective in reducing length of hospital stay? Int Orthop. 2013;37(6):1157-63

19. Scholes C, Cowley M, Ebrahimi M, Genon M, Martin SJ. Factors affecting hospital length of stay following total knee replacement: a retrospective analysis in a Regional Hospital. J Knee Surg. 2021;34(5):552-60.

20. Mathijssen NM, Verburg H, van Leeuwen CC, Molenaar TL, Hannink G. Factors influencing length of hospital stay after primary total knee arthroplasty in a fast-track setting. Knee Surg Sports Traumatol Arthrosc. 2016;24(8):2692-6.
21. Maiorano E, Bodini BD, Cavaiani F, Pelosi C, Sansone V. Length of stay and short-term functional outcomes after total knee arthroplasty: Can we predict them? Knee. 2017;24(1):116-20.

22. Moucha CS, Weiser MC, Levin EJ. Current strategies in anesthesia and analgesia for total knee arthroplasty. J Am Acad Orthop Surg. 2016;24(2):60-73.

23. Baldawi M, McKelvey G, Saasouh W, Perov S, Mostafa G, Saleh K. A comparison of neuraxial and general anesthesia for thirty-day postoperative outcomes in united states veterans undergoing total knee arthroplasty. J Arthroplasty. 2020;35(11):3138-44.

24. Matharu GS, Garriga C, Rangan A, Judge A. Does regional anesthesia reduce complications following total hip and knee replacement compared with general anesthesia? An analysis from the National Joint Registry for England, Wales, Northern Ireland and the Isle of Man. J Arthroplasty. 2020;35(6):1521-1528.e1525.

25. Harsten A, Kehlet $\mathrm{H}$, Toksvig-Larsen S. Recovery after total intravenous general anaesthesia or spinal anaesthesia for total knee arthroplasty: a randomized trial. Br J Anaesth. 2013;111(3):391-9.

26. Palanne R, Rantasalo M, Vakkuri A, Madanat R, Olkkola KT, Lahtinen K, Reponen E, Linko R, Vahlberg T, Skants N. Effects of anaesthesia method and tourniquet use on recovery following total knee arthroplasty: a randomised controlled study. Br J Anaesth. 2020;125(5):762-72.

27. Abdullah HR, Sim YE, Hao Y, Lin GY, Liew GHC, Lamoureux EL, Tan MH. Association between preoperative anaemia with length of hospital stay among patients undergoing primary total knee arthroplasty in Singapore: a single-centre retrospective study. BMJ Open. 2017;7(6):e016403.

28. Warren J, Sundaram K, Anis H, Kamath AF, Mont MA, Higuera CA, Piuzzi NS. Spinal anesthesia is associated with decreased complications after total knee and hip arthroplasty. J Am Acad Orthop Surg. 2020;28(5):e213-21.

\section{Publisher's Note}

Springer Nature remains neutral with regard to jurisdictional claims in published maps and institutional affiliations.
Ready to submit your research? Choose BMC and benefit from:

- fast, convenient online submission

- thorough peer review by experienced researchers in your field

- rapid publication on acceptance

- support for research data, including large and complex data types

- gold Open Access which fosters wider collaboration and increased citations

- maximum visibility for your research: over $100 \mathrm{M}$ website views per year

At BMC, research is always in progress.

Learn more biomedcentral.com/submissions 